\title{
Using Artificial Intelligence for Developing English Language Teaching/Learning: An Analytical Study from University Students' Perspective
}

\author{
Turki Rabah Al Mukhallafi ${ }^{1}$ \\ 1 Department of English Language, College of Arts and Sciences, Rafha Male Campus, Northern Border \\ University, Kingdom of Saudi Arabia \\ Correspondence: Turki Rabah Al Mukhallafi, Department of English Language, College of Arts and Sciences, \\ Rafha Male Campus, Northern Border University, P. O. Box 2173, Rafha, Kingdom of Saudi Arabia. E-mail: \\ hoppy4u@hotmail.com
}

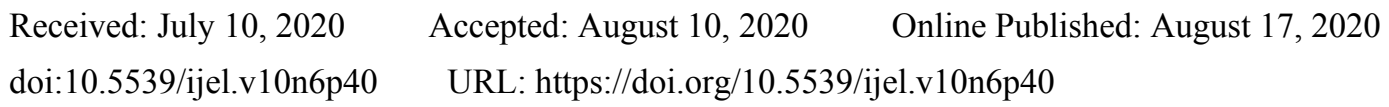

\begin{abstract}
As time passes on, machines are becoming more and more complex, fast-processing and intelligent. Being exactly like humans deducting, inferring and making decisions is still away, however some remarkable gains in the application of Artificial Intelligence (AI) techniques and machine learning have been recently recorded. Therefore, the current study seeks to examine strategies for effectively applying artificial intelligence (AI) applications to teach/learn English according to the university students' point of view. The study adopts the analytical descriptive approach in order to study and analyze the literature, to describe AI and the strategies of its employment for teaching/learning English. A 40-item questionnaire was used. It covers the following fields: AI strategies and its suitable applications for teaching/learning English, the effectiveness of these applications, their practical use, and the requirements for using them in the fields of teaching/learning English. Measuring the validity and reliability of the questionnaire revealed a Cronbach's alpha of 0.931 .

The study sample consisted of 44 randomly selected male students from the English language stream at Northern Border University. A set of study instruments was applied. The results revealed a group of strategies suitable for employing AI for teaching/learning English. The results also indicated a very low level of employment of these strategies for teaching/learning English, and pointed out to their effectiveness if used in this field. The study has identified the training requirements from the study sample's point of view. A suggested plan has been envisioned that includes the basics, objectives, content, processors, and evaluation methods for the employment of AI applications in the field of English education.
\end{abstract}

Keywords: English language teaching, Artificial Intelligence (AI), university students

\section{Introduction}

English language teaching is considered an essential educational objective in terms of developing students' ability to globally communicate. Raphael (2017) indicates that English language learning is one of the necessary educational objectives at a personal, academic, and occupational level. It is dependent on the educational programs and methods that focus on building incentives and positive attitudes towards language learning, and employing skills in communicating, teaching and learning.

Walker et al. (2017) highlighted the importance of using AI applications for creating written texts, developing students' skills in constructing sentences and building up texts, and practicing writing and reading skills. Along the same vein, Lotze (2016) added that employing AI applications help develop English language skills and language communication skills through intelligent dialog boxes. Language development processors are enhanced by a variety of intelligent sources, windows for dialogs and discussion, intelligent tools for communication, programs that generate texts for reading, and programs that extract information from reading passages. Such props develop reading comprehension skills.

\subsection{Study Objective}

The objective of the study is to determine the strategies and methods of employing AI for teaching/learning the 
English language, the effectiveness of these strategies, and the university students' perspective on the viability of applying them. The study also aims to determine the methods of employing AI applications for the development of programs related to English teaching/learning.

\subsection{Research Problem and Questions}

The problem of the current study is the low level of language skills among English learners. This is due to the usage of traditional strategies for teaching and building language skills. In order to address this problem, the present study attempts to answer the following questions:

- What are suitable strategies and methods for employing AI for teaching/learning English from the university students' perspective?

- How effective is the employment of AI for developing the processes and outcomes of teaching/learning English from the university students' perspective?

- To what extent is the employment of AI viable for teaching/learning English from the university students' perspective?

- What is the level of AI employment for teaching/learning English from the university student's point of view?

- What are the needs and requirements necessary for using AI in teaching/learning English from the university student's point of view?

\subsection{Research Objectives}

The Present Study Aims to:

- Measure the levels and effectiveness of the employment of AI applications for teaching/learning English from the university students' perspective.

- Prepare a conceptualization for the employment of AI applications for teaching/learning English. This would contain the basics, objectives, content, strategies, processors, and evaluation methods.

\subsection{Significance of the Study}

The present study could be of reasonable importance for:

- University students by helping them make use of educational AI applications in learning English.

- Designers of language learning programs by helping them identify AI applications and how they can be employed to develop educational curricula within their content and educational activities.

- Educational supervisors and language instructors to develop English teaching processors and strategies, develop academic advisory programs and evaluation tools and methods.

\subsection{Limitation of the Study}

The present study is limited to the following:

- AI applications for teaching/learning English through the use of technological applications, language learning applications, and smart and expert systems.

- Tools of the present study are applied during the first term of the academic year 2019/2020.

- Tools are applied at Northern Border University

- A sample of the first year from the English language department at Northern Border University.

\subsection{Terminology}

Artificial Intelligence (AI):

Al-Shawabkah $(2017$, p. 23$)$ defines AI as the abilities transmitted to computers to enable many performance systems to be smart and to resemble humans in their behavior. It is also defined as one of the fields of computer and information technology, which studies, designs, and develops computer systems that simulate human intelligence.

Artificial intelligence (AI) is defined in the present study as the application of AI systems for teaching/learning English in order to develop the processes of organizing and selecting scientific content. It also diversifies learning sources and educational streams according to the learners' levels. In addition, it is employed to develop teaching strategies and evaluation methods by individualizing self-study processes, and simulating through smart and expert systems. 


\subsection{Theoretical Background}

This section tackles the concept of AI, its justification, its applications in the field of education in general, and its applications in the field of teaching/learning English in particular. This is done in order to identify its uses in the field of teaching/learning English, its importance, and how it is applied.

\subsubsection{The Concept and Components of Artificial Intelligence (AI) and the History of Its Development}

Entering the 21 st century has been accompanied by many radical changes in the educational system as far as learning inputs, processes, and outcomes are concerned. Smart machines as applications of AI contribute to changing the roles played by schools, teachers, and learners. They will also change the traditional and virtual patterns of interaction in the educational milieu. Both teachers and learners will be dealing with interactive machines in order to share educational experiences, and to achieve the required objectives. These machines will offer interactive educational platforms that conduct discussions with the students and respond to their questions and reactions. They will solve traditional classroom problems such as paying attention and motivation, care for individual differences among learners, and support those with special needs. They will also provide solutions to the problem of interaction in large classrooms, giving feedback, improving the levels of student achievement, and developing positive attitudes towards teaching/learning. All of these aspects will be directly and positively affected by employing AI applications in the teaching/learning process (Dickenson, 2017, p. 105).

AI was recognized for the first time in 1956 by John McCarthy. At the time, it generated a considerable number of disputes and controversies around "Can machines think?" and the difference between human intelligence and AI was studied. AI is one of the modern computer sciences, which seeks developed methods of programming to achieve some tasks that simulate to some extent humans do in everyday life as it depends on simulating human intelligence. Theoretically, this science focuses on interpreting the concept of human intelligence, its patterns, and dimensions. It examines the mental abilities of the human mind in real life situations in order to simulate some of its skills and procedures. Then it translates these mental processes into computer equations used to solve complex problems. 'Expert Systems' is an AI branch that collects and analyzes data on human experiences in order to simulate and employ them in specific fields. These mental simulations are constantly developed by Expert Systems in accordance with the situations and problems to which people are exposed while dealing with AI devices. This leads to boosting the educational process by producing the correct decisions (Al-Feqi, 2012, p. 193).

Qammourah, Muhammad, and Krosh (2018, p. 6) illustrated that he science of AI consists of two main parts:

- Memory: This is represented by the mental activities related to storing, and it is a form of intelligence called 'negative intelligence'.

- Inference: This is the ability to analyze and realize the relationships among things in order to understand facts through memory and logic.

\subsubsection{AI Applications for Education}

Shabakah (2012, p. 28) explains that the main objectives of AI relate to simulating specific human processes and activities such as learning, thinking, and processing natural language through the technology of knowledge representation. Al-Gayyar's study (2013, pp. 503-504) indicates that AI applications vary, and that smart systems of online electronic learning are among the most important smart educational systems. These are the most significant applications of AI use in education. They are the outcome of merging many systems and applications in the field of AI such as:

- Intelligent Tutoring Systems

- Activating the Internet

- Activating hypermedia

- Activating distance E-education

Muhammad's study (2014, p. 18) refers to the varied applications of AI, which include electronic neural networks, developed hybrid systems, applications of developmental algorithms, electronic auto-copying, adaptive electronic platforms, bio-robots, Nano-technology, chemical and organic systems, and advanced controlling systems. Azmi, Mubariz, and Isma'il (2014, p. 237) asserted that these applications form an integrated network that can develop and update the education process at the levels of inputs, processes, and outputs.

As highlighted by Kamel, Al-Jazzar, and Mahmoud (2010, p. 220) AI applications are characterized by 
interaction between learners and open sources and tools. They also merge real life and virtual reality in an attractive educational milieu and make it possible to use virtual labs. AI education applications are determined according to the following items (p. 214):

- Natural language processing programs: These are associated with other programs and systems that can comprehend and generate language. The student interacts with the computer in natural language and the computer understands it.

- Machine programming: The student uses the computer to make software automatically in order to interpret or translate input data.

- Computerized man or robots: The robots can be used to carry out supplementary educational tasks in the school.

- The computer's ability to see through photo sensors. The computer can analyze pictures and drawings to recognize people and shapes.

- Computer games: These include competitive games that a learner can play against the computer.

- Expert systems: These enable students to build databases in specific fields, which can be used to resolve problems and analyze real life situations.

- Computer-based learning: Computers are used in the management of teaching/learning processes, giving instructions to students, and storing and retrieving educational experiences. All of this is implemented in a smart self-study environment.

Borge (2016, pp. 10-11) indicates the importance of AI applications in analyzing and producing the results of student evaluation processes at the university and pre-university stages. AI makes it easy for instructors to measure their students' levels precisely, which is something often difficult to achieve. It enables university teaching staff to assess the level of the educational processors and determine deficiencies in the lectures, scientific content, and the educational material introduced to students. AI helps meet the needs of each student according to his/her abilities and needs by introducing home assignments and monitoring the scores obtained by each student because it has smart programs that identify the students' common mistakes, gives the instructors hints as to what the problems are, and introduces instant feedback in a file designed separately for each student. Furthermore, AI tools and programs can cope with classroom density.

From the information above, it can be concluded that AI focuses on two issues. The first, the theoretical issue, relates to describing and interpreting mental processes and activities and representing human behavior in real tasks and situations. On the other hand, the second or applied issue, is concerned with employing smart tools and machines to represent human behavior. AI includes some applications that can generally be employed to perform educational tasks such as representing and storing knowledge, introducing varied models for student-student and student-machine interaction. AI can enhance the learning process with programs that translate accurately between English and Arabic according to modern dictionaries, which provide an accurate meaning of the vocabulary items according to their contexts. These programs can introduce some ideas about the reading passages, arrange words to make sentences and paragraphs, and use sounds to identify letters and words. They can identify word maps and link texts, pictures and sounds together.

\subsubsection{The Significance and Justifications for Employing AI}

Employing AI applications for education is a current trend in the field of experimental research. Studies refer to the diversification of AI education applications, which include programmed learning and other open source high technology. The importance of AI applications in education is determined by their ability to suit the needs and abilities of the learners, to work according to their educational preferences, and to monitor the progress rate of each learner. These applications contain tracks that suit all learners despite differences among their levels, boost their learning motivation, and cope with students' low levels of attention. They provide feedback that indicates student achievement levels and points of weakness and strength in the scientific content. They ensure that the curriculum subjects are integrated, that the parts of each subject follow logically, and that the learner has mastered one section before moving on to a more advanced one. The scientific content can be introduced in the form of problems, which the students work out according to their self-study streams. Instructors monitor this process and provide guidance and feedback. AI tutoring systems can replace instructors as they have programs that provide guidance automatically and enable learners to use self-study skills (Kamuka, 2015, p. 88).

The study by Cautela et al. (2019, p. 128) indicates that there is a link between AI applications and many thinking skills such as designing skills, which are highly sought after in the 21st century. Calp's study (2019, p. 
20) has illustrated that AI moves education from a traditional form to an automated education, or education through smart interactive machines. It employs natural language to produce new knowledge, and to boost supplementary educational tasks. AI applications can individualize tutoring and introduce varied educational models and streams in which languages are merged with fields of related knowledge. Thus, they offer students the chance to learn according to flexible streams that suit their different abilities and academic levels.

\subsubsection{AI and Teaching English}

Teaching English as a second language requires training in and practicing language skills. Since the opportunity to practice these skills in real life situations are often not available, students' chances of mastering these skills are diminished. Therefore, it is necessary to switch from traditional strategies to communicative ones, and rely on digital tools to face difficulties in teaching/learning English (Haupinm, 2016, p. 4).

Teaching English as a foreign language is regarded as an essential in modern life. The main aim of teaching English is to develop communicative competence, which is achieved through knowing how to use language elements and vocabulary to develop the skills of listening, speaking, reading, and writing. It also includes how to use language to produce texts, and how to use it to understand reading passages. The process of language development is based on communication as a goal and as a process. Therefore, using both traditional and digital communication strategies in the teaching/learning processes and activities is necessary. Thus, it is necessary to use AI applications such as simulation and communication programs as these simulate real life situations for conversation and communication in English, introduce practical training in language skills, and educational games based on language. Communication tools based on AI help design situations for practicing the accurate pronunciation of letters and words through sound drills and visual media. Such tools provide exercises for describing and interpreting images and everyday situations, for listening, and for practicing guided pronunciation. They also allow learners to practice language skills and provide feedback for guidance. Some programs have language drills that give training in communication through using language skills to guarantee that learners reach proficiency levels (Barnes, 2016, p. 6).

Radwan (2017, p. 2) indicates that AI can be used to overcome many of the difficulties of teaching/learning English:

- Using Information Retrieval techniques to build the ability to comprehend reading passages.

- Employing Machine Translation to develop students' translation skills.

- Using Automatic Speech Recognition techniques to learn correct pronunciation.

- Using Text-to-Speech techniques for blind and visually impaired students.

- Using open digital language dictionaries to enrich the student's vocabulary.

- Using intelligent programs to augment speaking skills for English learners.

- $\quad$ Employing a writing evaluation technique to teach paragraph and essay writing.

\section{Method}

The present study used the analytic descriptive approach to study and analyze a specific phenomenon. Earlier studies were analyzed to describe the concept of AI, its components, and its applications in the field of teaching. The study outlined AI applications for teaching/learning English in order to build a study tool and to determine study content. The paper focused on examining the extent to which AI can be applied to English language learning, how effective it is, and what practical methods can be used to apply it.

\subsection{Study Tools}

A questionnaire was designed to measure the point of view of a sample of university students. The questionnaire content has been determined as in Table 1 below. 
Table 1. Describing the content of the study tool (the questionnaire)

\begin{tabular}{|c|c|c|c|}
\hline No. & Field of the Questionnaire & Description & No of Items \\
\hline 1 & $\begin{array}{l}\text { Understanding AI strategies and } \\
\text { applications for teaching/learning } \\
\text { English. }\end{array}$ & $\begin{array}{l}\text { Sample's awareness of AI, its concepts, components, and applications. In } \\
\text { addition, they should know about its strategies for teaching/learning } \\
\text { English as far as program design, teaching strategies, and evaluation } \\
\text { methods are concerned. }\end{array}$ & 8 \\
\hline 2 & $\begin{array}{l}\text { The effectiveness of AI } \\
\text { applications in teaching/learning } \\
\text { the English language }\end{array}$ & $\begin{array}{l}\text { Sample's vision of the importance and effect of using AI applications on } \\
\text { developing the processes and activities of learning English and enhancing } \\
\text { the language skills (listening, speaking, reading, and writing) }\end{array}$ & 10 \\
\hline 3 & $\begin{array}{l}\text { Actual use of AI applications for } \\
\text { teaching/learning English }\end{array}$ & $\begin{array}{l}\text { Assessment of the levels of using AI applications for teaching/learning } \\
\text { English from the sample's point of view }\end{array}$ & 12 \\
\hline 4 & $\begin{array}{l}\text { Needs for and methods of using AI } \\
\text { applications for teaching/learning } \\
\text { English }\end{array}$ & $\begin{array}{l}\text { Studying the needs, requirements, methods, and rules of using AI } \\
\text { applications for teaching/learning English from the sample's point of view }\end{array}$ & 10 \\
\hline Total & & & 40 \\
\hline
\end{tabular}

The tool was presented in its original form. It consisted of two parts: the first relates to the fundamental data of the sample, and the second is concerned with the questionnaire items. The tool employed the 5-point Likert scale (very strongly agree $=5$, strongly agree $=4$, agree $=3$, somewhat agree $=2$, a little agree $=1$ ) and the tool has been set in its original form.

\subsection{Measuring Tool Validity}

The questionnaire's validity has been revised by eight of the university teaching staff specializing in teaching methodology, curricula and psychological testing. The correlation between each item and the field it measures, and the correlation between all the items and the tool as a whole have been studied. The tool was rewritten in the light of the referees' notes and returned to its original form. Then, it was applied to a sample of 32 students of English at the university. Internal consistency has been tested by calculating Pearson's correlation coefficient of the item's score in relation to the total score of the axis it measures. The results are shown in Table 2 below.

Table 2. Pearson's correlation coefficients for measuring the validity of the questionnaire's internal consistency

\begin{tabular}{|c|c|c|c|c|c|c|c|}
\hline Item No. & $\begin{array}{l}\text { Correlation } \\
\text { coefficient }\end{array}$ & Item No. & $\begin{array}{l}\text { Correlation } \\
\text { coefficient }\end{array}$ & Item No. & $\begin{array}{l}\text { Correlation } \\
\text { coefficient }\end{array}$ & Item No. & $\begin{array}{l}\text { Correlation } \\
\text { coefficient }\end{array}$ \\
\hline 1 & $0.66^{* *}$ & 11 & $0.71 * *$ & 21 & $0.83 * *$ & 31 & $0.75^{* *}$ \\
\hline 2 & $0.72 * *$ & 12 & $0.58 * *$ & 22 & $0.87 * *$ & 32 & $0.77 * *$ \\
\hline 3 & $0.77 * *$ & 13 & $0.68 * *$ & 23 & $0.72 * *$ & 33 & $0.64 * *$ \\
\hline 4 & $0.69 * *$ & 14 & $0.70 * *$ & 24 & $0.64 * *$ & 34 & $0.73 * *$ \\
\hline 5 & $0.73 * *$ & 15 & $0.69 * *$ & 25 & $0.75 * *$ & 35 & $0.65 * *$ \\
\hline 6 & $0.81 * *$ & 16 & $0.65^{* *}$ & 26 & $0.63^{* *}$ & 36 & $0.70 * *$ \\
\hline 7 & $0.59 * *$ & 17 & $0.60 * *$ & 27 & $0.71 * *$ & 37 & $0.88 * *$ \\
\hline 8 & $0.63 * *$ & 18 & $0.76^{* *}$ & 28 & $0.80 * *$ & 38 & $0.83 * *$ \\
\hline 9 & $0.78 * *$ & 19 & $0.82 * *$ & 29 & $0.65 * *$ & 39 & $0.58 * *$ \\
\hline 10 & $0.61 * *$ & 20 & $0.67 * *$ & 30 & $0.79 * *$ & 40 & $0.68 * *$ \\
\hline
\end{tabular}

Note. $(* *)$ Function at value $(0.01),\left(^{*}\right)$ Function at value $(0.05)$.

Table 2 shows that the meaning of Pearson's $r$ values ranges from high to intermediate values. The values of all of the questionnaire items show positive correlations; hence, the validity of the questionnaire's internal consistency is acceptable for the questionnaire items.

\subsection{Measuring Questionnaire Reliability}

The questionnaire reliability was measured using Cronbach's alpha for the fields and for the tool as a whole. Table 3 below shows the results:

Table 3. Cronbach's alpha for measuring tool reliability

\begin{tabular}{llll}
\hline No. & Questionnaire fields & No of items & Cronbach's alpha \\
\hline $\mathbf{1}$ & Understanding AI strategies and applications for teaching/learning English & $\mathbf{8}$ & $\mathbf{0 . 7 6 8}$ \\
$\mathbf{2}$ & The effectiveness of AI applications in teaching/learning the English language & $\mathbf{1 0}$ & $\mathbf{0 . 8 3 3}$ \\
$\mathbf{3}$ & Actual use of AI applications for teaching/learning English & $\mathbf{1 2}$ & $\mathbf{0 . 8 5 7}$ \\
$\mathbf{4}$ & Needs for and methods of using AI applications for teaching/learning English & $\mathbf{1 0}$ & $\mathbf{0 . 8 1 4}$ \\
The questionnaire as a whole & $\mathbf{4 0}$ & $\mathbf{0 . 9 3 1}$ \\
\hline
\end{tabular}




\subsection{Original Community and Study Sample}

The original community consists of university students of English, and the study sample consists of 44 students randomly chosen.

\subsection{Procedures of Field Application}

The study tool was applied during the first term of the academic year 2019/2020. The individuals in the sample were informed of the study objectives and the response mechanism. They were contacted via social media to answer their inquiries about the concepts and terms of the questionnaire. students' inquiries showed that they were highly motivated to use AI applications in teaching/learning English. They were also prepared to understand the strategies of using the applications. Responses to the questionnaire were returned in a week and the data were encoded and prepared for statistical processing with SPSS.

\subsection{Statistical Processing of the Study}

- Using Pearson's correlation coefficient to test the validity of internal consistency and Cronbach's alpha for the reliability of the questionnaire.

- Calculating the means and standard deviations of the fields and items to describe the responses of the study sample.

- Determining the levels of item availability to the sample by converting the separate Likert scale to a continuous one and interpreting the means according to the following indicators:

1) Available/considerably important: the range of mean values: (4.20-5.00).

2) Available/very important: the range of mean values: (3.40-4.20).

3) Available/important: the range of mean values: (2.60-3.40).

4) Available/somewhat important: the range of mean values: (1.80-2.60).

5) Available/a little important: the range of mean values: (1.00-1.80).

\section{Results}

Answer to the first question: What are suitable strategies and methods for employing AI for teaching/learning English from the university students' perspective?

Table 4. Means, standard deviations, and rating levels of the field of (strategies and methods of employing AI for teaching/learning English from the university students' perspective)

\begin{tabular}{|c|c|c|c|c|c|}
\hline No & Items & Mean & $\begin{array}{l}\text { Standard } \\
\text { deviation }\end{array}$ & $\begin{array}{l}\text { Rating } \\
\text { level }\end{array}$ & order \\
\hline 1 & $\begin{array}{l}\text { Linking AI as one of the outcomes of the digital cognitive revolution to the } \\
\text { outcomes of learning English }\end{array}$ & 3.87 & 1.13 & high & 8 \\
\hline 2 & $\begin{array}{l}\text { AI applications include intelligence, memory, inference processes, and human } \\
\text { intelligence simulation processes }\end{array}$ & 4.07 & 0.98 & high & 5 \\
\hline 3 & $\begin{array}{l}\text { Expert system applications as part of the AI educational applications used for } \\
\text { designing curricula and organizing the educational experiences of teaching English }\end{array}$ & 4.37 & 0.86 & $\begin{array}{l}\text { Very } \\
\text { high }\end{array}$ & 3 \\
\hline 4 & $\begin{array}{l}\text { Employing applications of natural language processors for teaching/learning } \\
\text { English, especially the ones related to the work of the brain and the cognitive } \\
\text { linguistic structure }\end{array}$ & 4.18 & 1.04 & high & 4 \\
\hline 5 & $\begin{array}{l}\text { Applications of translation programs and employing them to develop the skills of } \\
\text { reading and writing and the translation of the English texts }\end{array}$ & 3.92 & 1.08 & high & 7 \\
\hline 6 & $\begin{array}{l}\text { Employing the interactive smart translation strategies by using smart tools to build } \\
\text { simultaneous interpretation skills and to edit texts written in English }\end{array}$ & 3.96 & 1.23 & high & 6 \\
\hline 7 & $\begin{array}{l}\text { Smart voice communication strategies and strategies of interactive communicative } \\
\text { language for designing and implementing the participatory educational situations } \\
\text { used in English classrooms }\end{array}$ & 4.56 & 1.34 & $\begin{array}{l}\text { Very } \\
\text { high }\end{array}$ & 1 \\
\hline 8 & $\begin{array}{l}\text { AI applications include smart educational systems for teaching English, especially } \\
\text { for developing teaching/learning practices }\end{array}$ & 4.43 & 1.28 & $\begin{array}{l}\text { Very } \\
\text { high }\end{array}$ & 2 \\
\hline \multicolumn{2}{|r|}{$\begin{array}{l}\text { Total of the first field: Suitable strategies of applying AI for teaching/learning the English } \\
\text { language }\end{array}$} & 4.17 & 1.01 & high & \\
\hline
\end{tabular}


Table 4 indicates the following:

- Based on the responses, the level of importance of the total of the first field (Suitable strategies of applying AI for teaching/learning English) is high and the mean values are (3.87-4.56), considered to be high and very high.

- Responses to the items relating to smart programs for voice communication, communicative and interactive language strategies, smart systems applications, and expert systems reflect a very high level of agreement. This refers to their great importance as strategies of applying AI for teaching/learning English from the point of view of the sample.

- The rest of the first field items reflect a high level of agreement, which indicates their importance as strategies of applying AI for teaching/learning English from the point of view of the sample.

Answer to the second question: How effective is the employment of AI applications in developing the processes and outcomes of teaching/learning English from the point of view of the university students?

Table 5. Means, standard deviations, and rating levels of the field of (effectiveness of AI applications in teaching/learning English)

\begin{tabular}{|c|c|c|c|c|c|}
\hline No & Items & Mean & $\begin{array}{l}\text { Standard } \\
\text { deviation }\end{array}$ & $\begin{array}{l}\text { Rating } \\
\text { level }\end{array}$ & order \\
\hline 9 & $\begin{array}{l}\text { Intelligent tools help solve problems of language teaching, especially } \\
\text { classroom density, classroom availability, availability of teaching material } \\
\text { suitable for language teaching. }\end{array}$ & 4.66 & 1.38 & $\begin{array}{l}\text { Very } \\
\text { high }\end{array}$ & 2 \\
\hline 10 & $\begin{array}{l}\text { AI applications augment self-study activities by providing varied cognitive } \\
\text { tracks and preference models. }\end{array}$ & 4.37 & 1.27 & $\begin{array}{l}\text { Very } \\
\text { high }\end{array}$ & 6 \\
\hline 11 & $\begin{array}{l}\text { Enhancing knowledge representation processes by smart machines, linking the } \\
\text { cognitive fields together, and simulating lab experiments through virtual } \\
\text { reality labs }\end{array}$ & 4.13 & 1.22 & high & 9 \\
\hline 12 & $\begin{array}{l}\text { Supporting students by simulating natural phenomena, and introducing } \\
\text { interpretation that enhances reading comprehension }\end{array}$ & 4.72 & 1.09 & $\begin{array}{l}\text { Very } \\
\text { high }\end{array}$ & 1 \\
\hline 13 & $\begin{array}{l}\text { AI applications boost highly complicated educational tasks that save time and } \\
\text { effort. }\end{array}$ & 3.93 & 0.96 & high & 10 \\
\hline 14 & $\begin{array}{l}\text { AI strategies augment students' attention and motivation levels so that they } \\
\text { may effectively take part in the language teaching process. }\end{array}$ & 4.18 & 0.85 & high & 8 \\
\hline 15 & AI applications enhance students' skill of listening to English. & 4.34 & 1.04 & $\begin{array}{l}\text { Very } \\
\text { high }\end{array}$ & 7 \\
\hline 16 & $\begin{array}{l}\text { AI applications enhance students' ability to master the skill of speaking in } \\
\text { English. }\end{array}$ & 4.38 & 1.39 & $\begin{array}{l}\text { Very } \\
\text { high }\end{array}$ & 5 \\
\hline 17 & $\begin{array}{l}\text { AI applications enhance students' ability to master the skill of reading in } \\
\text { English. }\end{array}$ & 4.41 & 1.24 & $\begin{array}{l}\text { Very } \\
\text { high }\end{array}$ & 3 \\
\hline 18 & AI applications enhance students' ability to write in English. & 4.39 & 1.17 & $\begin{array}{l}\text { Very } \\
\text { high }\end{array}$ & 4 \\
\hline \multicolumn{2}{|c|}{ Total of the second field: Effectiveness of AI applications in teaching/learning English } & 4.35 & 1.26 & Very high & \\
\hline
\end{tabular}

Table 5 indicates the following:

- Based on the responses, the level of importance of the entire second field (Effectiveness of AI applications in teaching/learning English) reflects a very high level of agreement, and the mean values are (3.93-4.72), considered as very high and high.

- Responses to the items concerned with the effectiveness of AI applications in simulation, solving education problems, especially organizing work with high-density classrooms, and the effectiveness of employing AI applications in order to master language skills (listening, speaking, reading, and writing) reflect a very high level of agreement.

- The remaining items in this field reflect a high level of agreement, which refers to the high level of effectiveness of AI applications in enhancing students' levels of attention and motivation, representing knowledge related to understanding English reading passages, and facilitating the implementation of highly complicated educational tasks. These tasks include analyzing students' performance in groups, assessing positive interactions, and offering instructions for mastering language skills, and other tasks that cannot be implemented 
effectively in traditional teaching/tutoring programs.

Answer to the third question: To what extent is the employment of AI viable for teaching/learning English from the university students' perspective?

Table 6. Means, standard deviations, and rating levels of the field of (Actual use of AI applications for teaching/learning English)

\begin{tabular}{|c|c|c|c|c|c|}
\hline No & Items & Mean & $\begin{array}{l}\text { Standard } \\
\text { deviation }\end{array}$ & $\begin{array}{l}\text { Rating } \\
\text { level }\end{array}$ & order \\
\hline 19 & $\begin{array}{l}\text { Mastering the AI techniques concerned with extracting information and } \\
\text { building the ability to understand reading passages }\end{array}$ & 2.97 & 1.18 & medium & 7 \\
\hline 20 & Employment of AI applications to recognize spoken words correctly & 2,74 & 1.09 & medium & 9 \\
\hline 21 & Employment of OCR techniques for the analysis of English texts & 2.53 & 1.32 & low & 11 \\
\hline 22 & $\begin{array}{l}\text { Using open digital language dictionaries to enrich the student's } \\
\text { vocabulary }\end{array}$ & 3.47 & 0.97 & high & 1 \\
\hline 23 & $\begin{array}{l}\text { Employment of the techniques of evaluating the writing skills in order } \\
\text { to train the students in these skills gradually }\end{array}$ & 3.29 & 1.26 & medium & 2 \\
\hline 24 & $\begin{array}{l}\text { Using smart programs to enhance the speaking skills of the students } \\
\text { majored in English }\end{array}$ & 3.22 & 1.03 & medium & 3 \\
\hline 25 & $\begin{array}{l}\text { Employment of evaluating writing-skill techniques at the levels of } \\
\text { paragraph and essay writing }\end{array}$ & 3.09 & 0.89 & medium & 5 \\
\hline 26 & $\begin{array}{l}\text { Employment of grading written-text techniques according to fixed } \\
\text { standards }\end{array}$ & 2.78 & 0.88 & medium & 8 \\
\hline 27 & Employment of AI applications for training in language skills & 2.99 & 0.79 & medium & 6 \\
\hline 28 & $\begin{array}{l}\text { Employment of smart software to include students with special needs in } \\
\text { teaching English activities }\end{array}$ & 2.43 & 0.91 & low & 12 \\
\hline 29 & $\begin{array}{l}\text { Employment of AI applications for designing programs that support the } \\
\text { talented and distinguished students (high achievers) }\end{array}$ & 3.19 & 1.18 & medium & 4 \\
\hline 30 & $\begin{array}{l}\text { Employment of AI strategies and intelligent tools to overcome } \\
\text { difficulties of English language learning }\end{array}$ & 2.56 & 0.93 & low & 10 \\
\hline \multicolumn{2}{|r|}{ Total of the third field: Actual use of AI applications in teaching/learning English } & 2.94 & 0.86 & medium & \\
\hline
\end{tabular}

Table 6 indicates the following:

- $\quad$ Based on the responses, the level of importance of the entire third field (Actual use of AI applications in teaching/learning English) reflects a medium level of agreement and the mean values are (2.43-3.47), considered as high, medium, and low.

- Responses to the item (Using open digital language dictionaries to enrich the student's vocabulary) reflect a high level of agreement, which refers to the actual use of this technique in language teaching. This result is logical because it is easy for students to deal with digital dictionary applications and use them to improve their vocabulary.

- Responses to most of the items reflect a medium level of agreement, which means that the employment of AI applications for teaching/learning English requires greater effort in order to master these applications and to make use of them in improving learning outcomes.

- Some items reflect a low level of agreement, which means that their employment level for language teaching/learning is very low, especially those related to OCR, written-text analysis, and smart applications for learning difficulties and students with special needs.

Answer to the fourth question: What are the needs and requirements for using AI applications for teaching/learning English from the university students' perspective? 
Table 7. Means, standard deviations, and rating levels of the field of (requirements of using AI applications for teaching/learning English)

\begin{tabular}{|c|c|c|c|c|c|}
\hline No & Items & Mean & $\begin{array}{l}\text { Standard } \\
\text { deviation }\end{array}$ & Rating & order \\
\hline 31 & $\begin{array}{l}\text { Laying a conceptual framework of AI, AI elements, and the justifications } \\
\text { for its employment }\end{array}$ & 4.01 & 1.13 & high & 9 \\
\hline 32 & $\begin{array}{l}\text { Determining AI applications in a procedural way in the teaching/learning } \\
\text { activities }\end{array}$ & 4.15 & 1.06 & High & 7 \\
\hline 33 & $\begin{array}{l}\text { Recognizing AI strategies in planning and managing the educational } \\
\text { situations }\end{array}$ & 4.37 & 1.27 & Very high & 5 \\
\hline 34 & $\begin{array}{l}\text { Offering models and examples of using AI applications in teaching/learning } \\
\text { English }\end{array}$ & 4.51 & 1.33 & Very high & 3 \\
\hline 35 & $\begin{array}{l}\text { Mastering the skills of program planning and teaching by using AI } \\
\text { applications for teaching English }\end{array}$ & 4.57 & 1.08 & Very high & 2 \\
\hline 36 & $\begin{array}{l}\text { Mastering the skills of program implementation and the employment of } \\
\text { teaching strategies by using AI applications for teaching English }\end{array}$ & 4.36 & 0.99 & Very high & 6 \\
\hline 37 & $\begin{array}{l}\text { Mastering the skills of learning management and educational open sources } \\
\text { by using smart educational tools for teaching English }\end{array}$ & 4.39 & 1.34 & Very high & 4 \\
\hline 38 & $\begin{array}{l}\text { Mastering actual evaluation skills and the evaluation based on performance } \\
\text { in the light of using AI applications for language learning }\end{array}$ & 4.68 & 1.61 & Very high & 1 \\
\hline 39 & $\begin{array}{l}\text { Employment of AI strategies and applications for learning and continuous } \\
\text { self-study }\end{array}$ & 4.09 & 0.87 & High & 8 \\
\hline 40 & $\begin{array}{l}\text { Mastering the mechanisms for the ongoing occupational development in the } \\
\text { light of AI applications }\end{array}$ & 3.86 & 0.92 & High & 10 \\
\hline \multicolumn{2}{|r|}{$\begin{array}{l}\text { Total of the fourth field: Requirements of applying AI strategies for } \\
\text { teaching/learning the English language }\end{array}$} & 4.30 & 1.25 & Very high & \\
\hline
\end{tabular}

Table 7 indicates the following:

- Based on the responses, the level of importance of the entire fourth field (Requirements of applying AI strategies for teaching/learning English) reflects a very high level of agreement, the mean values are (3.86-4.68), and the rating of the items is very high, and high.

- The responses concerned with the requirements for some items reflect a very high level of agreement, especially items related to mastering skills in employing AI applications and smart tools in student performance evaluation and using them for planning and implementing teaching strategies for teaching/learning English.

- The responses related to the requirements of some items reflect a high level of agreement, especially those related to understanding AI concepts, applications, and strategies, and employing them for self-study, and continuous occupational self-development.

Based on the results of the present study, it is possible to determine a set of strategies for employing AI applications for teaching/learning English. These strategies depend on smart and expert systems. The study has emphasized the effectiveness of these systems in developing the learning outcomes of teaching/learning the English language. The study results indicated the deficiencies in applying AI applications in this process. The study has also determined a set of training requirements necessary for implementing these strategies and applications. The results are considered to be consistent and logical, and the low levels of actual use of AI applications relates to the training needed to implement these applications.

The results of the present study are compatible with Al-Gayyar's study (2014), which emphasizes the importance of employing AI applications in the teaching/learning programs for their effectiveness. In addition, strategies and practical application of AI programs should be mastered. The results agree with those of Al-Far and Shahin (2019) in the field pertaining to the effectiveness of smart applications in teaching and learning, especially in abstract processes. They are consistent with the results of Al-Omari's study (2019), which has indicated the importance of training in using AI applications especially for their effectiveness in developing cognitive aspects. They concur with the results of Al-Yajizi's study (2019), which indicates that it is necessary to offer university staff training in how to employ AI applications for university education according to their needs. The results are compatible with the study of both Al-Farrani and Al-Hejaili (2020), which indicate the effectiveness of AI applications in discovering the multiple talents of students and their importance in determining students' educational and cognitive preferences, and consequently the streams they may join. 
Answer to the fifth question: What is the conceptualization suggested for employing AI applications in teaching/learning the English language? This has been suggested according to the following:

- $\quad$ AI applications are part of contemporary trends, so it is necessary to employ them in university teaching as part of 21 st century skills and the nature of the digital world and its requirements.

- Employment of AI applications and strategies relates to studying and accurately determining training needs in order to boost procedural practices in the light of AI strategies for teaching/learning English.

- AI strategies vary. They include interactive smart translation strategies through smart tools and software, voice communication strategies, strategies for diversifying scientific content and digital open sources, and strategies for communicative language teaching (enhanced with interactive voice and images). They also include strategies suitable for difficulties in language communication, strategies for computer simulation, and employment of smart programs with the help of expert systems. These are multiple programs that depend on simulation to develop skills through dialog boxes and interaction.

- The nature of the English language requires the employment of strategies suitable for the skills of listening, speaking, reading, and writing. To achieve this, smart tools, expert systems based on interaction and student sharing are used.

\section{Objectives of the suggested conceptualization:}

Objectives of the suggested conceptualization relate to the development of processes and activities of English language teaching/learning. This includes the skills and the cognitive and affective aspects at the level of designing, evaluating, and implementing the teaching process. The details of the suggested concept include:

- Identifying the concepts of AI and smart tools.

- Determining AI strategies and applications for education.

- Determining the AI strategies suitable for teaching English.

- Mastering making teaching plans according to AI strategies.

- Mastering teaching according to AI strategies.

- Mastering the evaluation of teaching according to AI strategies.

- The employment of AI applications for students' self-study.

- The employment of AI applications for continuous occupational development.

\section{Contents of the suggested conceptualization.}

Based on the training needs and the procedural goals of the suggested conceptualization, it is possible to determine a set of main and secondary topics related to this in accordance with the following:

- Conceptual framework: This is related to the study of the AI concept, its requirements, systems and justifications for teaching and learning.

- $\quad$ AI applications and strategies: Determining the AI strategies suitable for teaching/learning English.

- The procedural framework: This includes training in the skills of planning, implementing, and evaluating the teaching process in the light of AI applications and strategies.

\section{Processes of the suggested conceptualization and methods of evaluation.}

Mechanisms for implementing the suggested conceptualization are based on using AI applications and participant self-training. Processing activities are gradually shown in a conceptual presentation based on discussion and interactive brainstorming. This is supplemented by training in the strategies, during smaller teaching presentations, interactive and thoughtful observation of the assessment, and studying the need to work on them during traditional and interactive training sessions.

\section{Suggestions of the Study}

Based on the results of the study, it is possible to suggest the following:

- The effectiveness of the program based on AI applications in developing the language skills of the university students.

- Studying the training needs of high school teachers of English in the light of the AI applications.

- $\quad$ Studying the training needs of the university teaching staff in the light of the AI applications and strategies. 


\section{References}

Ageh, K. (2019). When Artificial Intelligence Met Public Procurement: Improving the World Bank's Suspension and Debarment System with Machine Learning. Public Contract Law Journal, 48(3), 565-595. Retrieved from http://search.ebscohost.com/login.aspx?direct=true $\& d b=a 9 h \& A N=138330777 \&$ site=ehost-live

Al-Far, I. A. W., \& Shahin, Y. M. M. (2019). The effectiveness of interactive chat robots to convey and instill the mathematical concepts in first prep year students. The Arab Association of Education Technology, 38, 541-571.

Al-Farrani, L. A. K., \& El-Hejaili, S. A. S. (2020). An educational scenario for using AI to discover the instructors' multiple facets of intelligence. The Arab Institution of Education, Sciences, and Literature, 11, 73-91.

Al-Feqi, A. I. M. (2012). Management of the electronic educational situations designed by motivation and its effect on student achievement and supporting the trend to use AI and expert systems by education technology students (pp. 187-215). The 13th Scientific Conference: Electronic Education Technology Current Trends and Issues: The Egyptian Association of Educational Technology. Cairo: The Egyptian Association of Educational Technology, Egypt.

Al-Gayyar, G. A. N. M. (2013). Employing Artificial Intelligence for building educational websites as a prelude to the development of electronic university learning. Future of Arabic education: The Arab Center for Education and Development, 20(82), 501-510.

Al-Omari, Z. H. Z. (2019). The Effect of using AI chat robots to develop the science subject cognitive aspects of primary stage female pupils. The Saudi Association for Educational and Psychological Sciences, 64, 23-48.

Al-Qaissi, A. S. J. N. (2010). Using AI applications for developing the teaching/learning process. Al Mansour University College, 14, 37-58.

Al-Shawabkah, A. A. (2017). The role of AI applications (Expert Systems) in making administrative decisions in the General Saudi Banks, Ta' if Governorate. Ta 'if University Magazine on Humanities, 49(15), 13-59.

Al-Yajizi, F. H. (2019). Using AI applications to enhance university education in KSA. Arab Educationalist League, 113, 257-282.

Azmi, N. G., Mubariz, M. A. A., \& Isma'il, A. R. M. (2014). The effectiveness of an electronic educational environment based on AI to solve the problems of maintaining computer networks of the education technology students. The Arab Association for Education Technology, 235-279.

Barnes-Hawkins, C. (2016). English language learners' perspectives of the communicative language approach. Doctor of Education, Walden University. Retrieved from https://search.proquest.com/docview/1810440594?accountid=178282

Blumenstyk, G. (2018, April 13). Can Artificial Intelligence Make Teaching More Personal? Chronicle of Higher Education, $1 . \quad$ Retrieved from http://search.ebscohost.com/login.aspx?direct=true \&db=a9h\&AN=131501744\&site=ehost-live

Boneau, A. (1993). Artificial Intelligence: Its reality and future (Ali Sabri Faghali Translator). Alam Al-Ma'rifah series. The National Council for Culture, Arts, and Literature: Kuwait.

Borge, N. (2016). White paper-Artificial Intelligence to Improve Education/Learning Challenges. International Journal of Advanced Engineering \& Innovative Technology, 2(6), 10-13.

Calp, H. (2019). Evaluation of Multidisciplinary Effects of Artificial Intelligence with Optimization Perspective. Broad Research in Artificial Intelligence \& Neuroscience, 10(1), 20-29. Retrieved from $\mathrm{http}: / /$ search.ebscohost.com/login.aspx?direct=true \&db=a9h\&AN=134949392\&site=ehost-live

Cassell, J. (2019). Artificial Intelligence for a Social World. Issues in Science \& Technology, 35(4), 29-36. Retrieved

from $\mathrm{http}: / /$ search.ebscohost.com/login.aspx?direct=true \&db=a9h\&AN=137577172\&site=ehost-live

Cautela, C., Mortati, M., Dell'Era, C., \& Gastaldi, L. (2019). The impact of Artificial Intelligence on Design Thinking practice: Insights from the Ecosystem of Startups. Strategic Design Research Journal, 12(1), 114-134. https://doi.org/10.4013/sdrj.2019.121.08

Clark, M. (2018). Artificial intelligence for the general interest. The world summit report on AI for the general interest, The World Union for Communication, Genève, Switzerland. 
Dickson, B. (2017). How Artificial Intelligence is Shaping the Future of Education. PC Magazine, 105-115. Retrieved from http://search.ebscohost.com/login.aspx?direct=true \&db=a9h\&AN=125789751\&site=ehost-live

El-Sayed, A. A. R. (1994). AI applications and models of neuro-networks in different scientific and educational fields. Banha University, Faculty of Education, 5(15), 147-158.

Farghali, A. (1988). Computer linguistics and AI: potentials for application in computerized language learning programs. The Council of Scientific Publications, 8(32), 192-193.

Fleming, S. C. (2003). A comparison of artificial intelligence-based asynchronous internet instruction and traditional instruction in community college developmental algebra (Order No. 3083062). Available from ProQuest Dissertations \& Theses Global. (305300515). Retrieved from https://search.proquest.com/docview/305300515?accountid=178282

Ge, X., Yin, Y., \& Feng, S. (2018). Application Research of Computer Artificial Intelligence in College Student Sports Autonomous Learning. Educational Sciences: Theory \& Practice, 18(5), 2143-2154. https://doi.org/10.12738/estp.2018.5.114

Ghazi, E. E. D. (2005). Artificial Intelligence: Is it a symbolic technology? Humanities and Social Sciences, 6 , 43-81.

Haupin, R. (2016). Improving receptive oral language skills of English language learners to enhance achievement in reading Recovery. Doctor of Education, Widener University. Retrieved from https://search.proquest.com/docview/1803233737?accountid=178282

Hennigan, T. A. (2000). Multiple intelligence and artificial intelligence: Educational implications of computers for learning interacting with multiple intelligences. University of Idaho. Available from ProQuest Dissertations \& Theses Global (304624393). Retrieved from https://search.proquest.com/docview/304624393?accountid=178282

Isa, S. A. H. M. (2009). A suggested plan for employing electronic learning for developing some mathematical concepts for the deaf through AI processors (pp. 1-35). The First International Conference on Electronic Learning and Distance Learning. Riyadh: Ministry of Higher Education and the National Center for Electronic Learning and Distance Learning.

Kamel, E. B. K., Al-Jazzar, A. A.-S., \& Mahmoud, S. (2010). Artificial Intelligence as a design variable of cooperative electronic learning and its effect on developing the cognitive achievement of educational situational designs by education technology students. Faculty of Education, 25(2), 212-257.

Kamuka, E. E. D. I. (2015). Artificial Intelligence in programmed Education. The Arab Institution for Scientific Counsel and Development of Human Resources, 49(1), 84-96.

Lancaster, F. W., Warner, A., Al-Tayyar, M. B. S., \& Al-Shelail, T. I. (2008). Applications of AI techniques and expert systems in libraries and information services. King Fahad National Library, 14(2), 394-400.

Lapata, M., \& Barzilay, R. (2005). Automatic evaluation of text coherence: Models and representations (pp. 1085-1090). In Proceedings of the 19th International Joint Conference on Artificial Intelligence (IJCAI).

Lotze, N. (2016). Chatbots Eine linguistische Analyse. Downloaded from PubFactory at 01/11/2019 10:18:51AM.

Lu, D. (2009). An artificial intelligence of expert system for college English teaching association. Beijing University of Chemical Technology. Available from ProQuest Dissertations \& Theses Global (1870463615). Retrieved from https://search.proquest.com/docview/1870463615?accountid=178282

McMurtrie, B. (2018, August 20). How Artificial Intelligence is Changing Teaching. Chronicle of Higher Education, $1 . \quad$ Retrieved from http://search.ebscohost.com/login.aspx?direct=true\&db=a9h\&AN=131759498\&site=ehost-live

Moratz, R., Fischer, K., \& Tenbrink, T. (2001). Cognitive modeling of spatial reference for human-robot interaction. International Journal on Artificial Intelligence Tools, 10(4), 589-611. https://doi.org/10.1142/S0218213001000672

Muhammad, N. S. E. (2014). Motivation applications in artificial intelligence. Unpublished M.A. thesis. Al-Neelain University, Khartoum.

Mujahid, F. A. H. (2020). AI applications and the development of everyday skills for people with special needs: 
A future look. The International Institution for Future Horizons, 3(1), 175-193. https://doi.org/10.29009/ijres.3.1.3

Nechita, E. (2014). Teaching Advanced Concepts in Artificial Intelligence. An Experiment. Annals of the University Dunarea de Jos of Galati: Fascicle II, Mathematics, Physics, Theoretical Mechanics, 37(2), 132-139.

Retrieved

from http://search.ebscohost.com/login.aspx?direct=true\&db=a9h\&AN=113376227\&site=ehost-live

Qammourah, S. S., Muhammad, B., \& Krosh, H. (2018). Artificial Intelligence between reality and the expected: A technical field study (pp. 1-19). The International Meeting entitled "Artificial Intelligence: A New Challenge for the Law". Algeria: November 26-27.

Radwan, Z. M. (2017). Artificial Intelligence and its impact on development. ASBAR Council. Retrieved December 1, 2017, from http://multaqaasbar.com/index.php

Raphael, N., Madoda, C., Baba, T., \& Sindiso, Z. (2017). Exploring the Second Language Teaching Strategies of Ndebele English Teachers in Selected Secondary Schools in Zimbabwe. Gender \& Behaviour, 15(2), $8626-8637$.

Shabakah, N. S. E. (2012). Artificial intelligence and the logic of representing knowledge: The logic of multiple-component material. Association of Faculties of Computers and Information, 1(2), 19-33.

Walker, M., Stent, A., Mairesse, F., \& Prasad, R. (2007). Individual and Domain Adaptation in Sentence Planning for Dialogue. Journal of Artificial Intelligence Research, 30. https://doi.org/10.1613/jair.2329

Wang, H., \& Chen, S. (2007). Artificial Intelligence Approach to Evaluate Students' Answerscripts Based on the Similarity Measure between Vague Sets. Journal of Educational Technology \& Society, 10(4), 224-241. Retrieved

from $\mathrm{http}: / /$ search.ebscohost.com/login.aspx?direct=true $\& \mathrm{db}=\mathrm{a} 9 \mathrm{~h} \& \mathrm{AN}=27801061 \&$ site=ehost-live

Ziegler, N. (2014). English language learners' epistemic beliefs about vocabulary knowledge. The University of Toledo. Available from ProQuest Dissertations \& Theses Global (1773492386). Retrieved from https://search.proquest.com/docview/1773492386?accountid=178282

\section{Copyrights}

Copyright for this article is retained by the author, with first publication rights granted to the journal.

This is an open-access article distributed under the terms and conditions of the Creative Commons Attribution license (http://creativecommons.org/licenses/by/4.0/). 